\title{
Editorial
}

\section{Del mito de las economías capitalistas a la realidad de las economías mixtas}

http://doi.org/10.14718/revfinanzpolitecon.v13.n2.2021.1

\section{Joan Miguel Tejedor-Estupiñán*}

El periodo de transición del feudalismo al capitalismo también está reflejado en el paso de la etapa preindustrial a la industrial. Durante varios siglos, el feudalismo y el capitalismo convivieron, mientras que este último se expandía por Europa y el mundo, fundamentado en las principales corrientes proteccionistas y librecambistas de los siglos XVIII y XIX. El mercantilismo fue una de las primeras escuelas económicas impulsadas desde finales del siglo XV y hasta el siglo XVIII desde las nuevas monarquías de Inglaterra, Francia, España, Portugal y Alemania, conformado por una serie de políticas para promover la protección y expansión del comercio exterior europeo.

Desde estas naciones, se creó la idea de que la intervención del Estado era fundamental para alcanzar los objetivos del pueblo (sin importar cómo y/o quién los definiera). En Inglaterra, el comercialismo fue inspirado por William Petty, Tomas Mun y James Steward, entre otros, quienes promovían el proteccionismo por medio de las cartas navales y el comercio exclusivo con Inglaterra; en Francia el colbertismo fue liderado por Jean Baptiste Colbert, Monchetrien, Jean Bodin, el Duque de Sully, entre otros, quienes consideraban que la riqueza de la nación dependía de la acumulación del oro y el desarrollo de la industria marítima; en España y Portugal el bullonismo fue promovido por Thomas Milles y Gerard de Malynes, quienes tenían claro que la riqueza de estos reinos dependía del monopolio de la acumulación del oro proveniente de las Américas; en Austria y Alemania el cameralismo fue estudiado por Johann Mathias Puechberg, Johann Heinrich Gottlob von Just y Robert Owen, quienes consideraban que era necesario promover políticas de sustitución de importaciones y consolidar un Estado fuerte y autárquico (Cameron y Neal, 2014).

Ph.D. (C) en Economía; Magíster en Derechos Humanos y Economista. Editor de la revista Finanzas y Política Económica de la Universidad Católica de Colombia. Dirección de correspondencia: Facultad de Economía, Universidad Católica de Colombia, Carrera 13 n. 47-49 (Bogotá, Colombia).Correo electrónico: jmtejedor@ ucatólica.edu.co. (D) ORCID: https://orcid.org/0000-0002-2346-3222 
La idea central del mercantilismo era que el poder del monarca dependía de la riqueza del país medida en la capacidad para acumular oro; por lo tanto, la forma más rápida de enriquecimiento era por vía del comercio exterior. Los Estados conformados en la época legislaban a favor de los intereses comerciales, prohibiendo o gravando las importaciones y exportaciones de productos, discriminando y estableciendo comercio exclusivo, concediendo monopolios de fabricación de algunos productos o de explotación de determinadas zonas, colonizando territorios principalmente en los continentes de América, África y Asia para obtener beneficios económicos, tanto en Europa como fuera de ella. El objetivo principal de las políticas mercantilistas era obtener balanzas de pago positivas que permitieran acumular oro dentro del país (Feliu y Sudrià, 2013).

Las políticas mercantilistas se caracterizaron por la discriminación y la ineficiencia, que encarecieron los productos, frenaron el comercio internacional y provocaron guerras. Además, incrementaron las cargas impositivas, mientras aumentaban los gastos militares y los lujos de la clase burócrata naciente, lo cual motivó grandes revueltas que iniciaron el proceso de abolición del absolutismo que tiene como punto de partida la revolución de Gran Bretaña de 1680, cuando el poder pasó a ser controlado por el parlamento en lo que concernía a la aprobación de nuevos impuestos y a la gestión del presupuesto. La abolición definitiva del feudalismo y de la monarquía absoluta y su sustitución por regímenes parlamentarios capitalistas tienen sus antecedentes en la Constitución de los Estados Unidos de América (1787) y la Revolución Francesa (1789). La implantación legal del capitalismo en el resto del continente europeo fue un proceso parsimonioso producido a lo largo de los dos primeros tercios del siglo XIX (Feliu y Sudrià, 2013).

El racionalismo criticó de manera directa al sistema económico feudal, considerando que la razón debe ser el principio rector de toda actividad humana y que, por lo tanto, el comportamiento racional se fundamenta en las leyes naturales que se deben complementar, mas no contradecir, por medio de leyes positivas. Dentro de los principales teóricos de esta corriente — que además creó el marco teórico para la consolidación de los Estados-, encontramos a René Descartes, Thomas Hobbes, John Locke, Jean Jackes Rousseau, David Hume y Montesquieu (Feliu y Sudrià, 2013). A quienes se unió en el siglo XVIII una corriente de pensamiento económica llamada la fisiocracia, representada por François Quesnay y su discípulo Jacques Turgot, y más adelante el padre de la escuela clásica Adam Smith, quienes consideraban que la actividad económica también estaba regulada por leyes naturales representadas en la libertad personal y de empresa, el derecho de propiedad y el mercado y, por consiguiente, actuando conforme a estas, se podría alcanzar el máximo provecho económico y crecimiento económico (Cameron y Neal, 2014). 
Mientras que para los fisiócratas la riqueza dependía del sector agrícola, el cual enriquecía a las tres clases sociales principales de la sociedad (campesinos, artesanos y terratenientes), para los clásicos la riqueza de las naciones dependía de la división del trabajo y la especialización en la producción en aquellos sectores donde se tuvieran ventajas absolutas. Estas dos escuelas tenían en común la idea de que el mercado debería funcionar sin la intervención estatal, ya que dudaban que gobiernos corruptos intercedieran por el bien de la sociedad en vez de por sus propios intereses.

Es aquí donde nace la idea de la libertad de empresa que da origen al liberalismo económico, la cual considera -en oposición al mercantilismo y su intervencionismo estatal - que el mercado puede funcionar mejor sin la intervención del Estado; mientras los fisiócratas promovían la política de laissez-faire et laisser-passer, que significaba dejar hacer a las empresas sin impuestos o restricciones estatales para su creación y producción, al igual que dejar pasar los productos en el mercado interno y externo de manera libre sin impuestos (Cameron y Neal, 2014). Sin embargo, quien más aporto al liberalismo económico fue Smith, economista que consideraba que el egoísmo era la fuerza que llevaba a los seres humanos a competir por la creación de mejores productos, por medio del progreso técnico derivado de la especialización, haciendo que las empresas más competitivas desplacen a las menos competitivas, en un mercado que funcionaría de manera libre. Aquí el sistema de precios muestra las preferencias de los consumidores, que finalmente compran los mejores productos y servicios que, en suma, mejorarían el bienestar de la sociedad en su conjunto, gracias a una mano invisible que llevaría al equilibrio a las fuerzas de la oferta y la demanda (Smith, 1776).

Sin embargo, el razonamiento de Smith no encontró eco en todos los pensadores sociales del siglo XIX, cuyas preocupaciones se centraban en las graves desigualdades en la distribución de la tierra y de la renta, la miseria y el paro en que vivían las clases trabajadoras. Aunque algunos escritores del siglo XIX, como Victor Hugo y Charles Dickens, describieron en sus novelas las precarias situaciones de las clases trabajadoras, algunos teóricos sociales, como Karl Marx, Sismondi y Robert Owen, desarrollaron teorías que, además de explicar la realidad que ellos percibían, sugerían propuestas para reorganizar mejor la sociedad; estos autores atribuían los males de la sociedad a la propiedad privada del capital. Lo que para Adam Smith era una virtud, para ellos era un defecto.

Por ejemplo, Marx fue uno de los defensores más influyentes de la idea de que el Estado debía intervenir en el control de los medios de producción. Sismondi atacó la idea de que el equilibrio económico llevaba al pleno empleo y a la felicidad, fue un crítico del laissez faire y un promotor de la necesidad de la intervención del gobierno en lo que respecta a 
la regulación del progreso y el bienestar, al tiempo que criticó firmemente la economía liberal en lo que respecta a la justicia social y a las crisis. Para Owen, la solución no se encontraba en manos del Estado ni de la empresa privada, sino en la formación de grupos más pequeños de personas que cooperaran en interés mutuo (Stiglitz y Rosengard, 2015). En 1915, el ruso Vladímir Lenin argumentó que el imperialismo era la última etapa del capitalismo, defendió fuertemente el control de los recursos y factores de producción por parte del Estado (Cameron y Neal, 2014).

Durante el siglo XX, por un lado, la propiedad privada y la libre empresa y, por el otro, el control estatal de los medios de producción serían los principios opuestos que continuarían guiando la política económica internacional. La primera mitad del siglo XX fue marcada por tres acontecimientos internacionales que cambiaron profundamente la percepción hacia el Estado: la Gran Guerra o Primera Guerra Mundial, la Gran Depresión de 1929 y la Segunda Guerra Mundial. John Maynard Keynes -inicialmente un promotor del libre cambio-, luego de la Gran Depresión, cuando el paro de Estados Unidos alcanzó el 25\% y su producción cayó un tercio con respecto al máximo registrado en 1929, cambió su postura creyendo firmemente que el Estado debía y podía intervenir en ciertas ocasiones, como en caso de que fuera necesario hacer frente a depresiones económicas. De este modo, la escuela keynesiana tenía como objetivo un Estado de bienestar que se podría alcanzar con intervención gubernamental, incrementando el gasto público como estrategia para generar empleo público que sacara a la economía de Estados Unidos de la crisis, y estimulara la demanda agregada, el ahorro y, en consecuencia, la inversión (Keynes, 1934).

En las primeras décadas del siglo XXI, los países de la antigua Unión Soviética, la antigua cortina de hierro e incluso China han venido desarrollando una transición y adaptación a un sistema de mercado, lo cual ha implicado una transformación fundamental del papel del Estado en estas economías. En los países occidentales, el papel económico del Estado también ha cambiado de manera gradual y en respuesta a acontecimientos económicos que han ido ocurriendo durante todo el siglo. Actualmente se ha extendido la idea de que los mercados y las empresas privadas constituyen la clave del éxito de una economía, mientras que el Estado desempeña un papel importante como complemento del mercado. Así se deriva un nuevo consenso en el cual el Estado debe ir reduciendo su tamaño gradualmente, facilitando el libre mercado y la privatización de las empresas públicas. Estos han sido algunos de los principales argumentos de los economistas neoliberales como el premio Nobel de economía Milton Friedman, uno de los más fervientes críticos del intervencionismo estatal. Ciertamente, la finalidad del papel del Estado actualmente es fuente de grandes controversias y varía de un país a otro incluso dentro de un mismo país (Stiglitz y Rosengard, 2015). 
Las diferentes crisis acontecidas en el último siglo han sido la justificación para que el Estado encuentre los argumentos para intervenir en las actividades económicas con el fin de hacer frente a todos los "fallos del mercado", entre los cuales se encuentran principalmente: la competencia imperfecta, los bienes públicos, las externalidades, los mercados incompletos, los fallos de la información y el paro. Al igual que los fallos del mercado, también se reconocen las limitaciones del Estado o "fallos del Estado", dentro de los cuales encontramos: la información limitada, el control limitado de las empresas privadas, el control limitado de la burocracia y las limitaciones impuestas por los procesos políticos; todos ellos dan como resultado unos programas públicos con consecuencias negativas que jamás se planearon. Friedman cree que estos fallos del Estado son razones suficientes para que este se abstenga de tratar de resolver las deficiencias de los mercados (Stiglitz y Rosengard, 2015).

De esta manera, junto a las anteriores crisis, la crisis del petróleo de 1979, la crisis financiera de 2008 y, más recientemente, la crisis mundial generada por el virus SARSCov-2, que provoca la enfermedad COVID-19, han puesto de nuevo en el centro del debate los límites entre las actividades públicas y privadas, dejando en evidencia cómo la mayoría de países occidentales funcionan bajo modelos de economía mixta donde muchas actividades son desarrolladas tanto por el Estado (por medio de empresas públicas) como por las empresas privadas. El premio Nobel de economía Joseph Stiglitz y el profesor de economía Jay Rosengard proponen, desde el punto de vista del capitalismo progresista, que para alcanzar el equilibrio entre el sector público y el sector privado, es posible que el Estado pueda corregir los fallos del mercado, reconociendo las limitaciones tanto del uno como del otro (fallos del mercado y del Estado) y promoviendo la actuación conjunta entre ambos.

En este sentido, es posible plantear que nos encontramos frente a economías mixtas, donde desde el sector público se esbozan cuatro preguntas principales: ¿qué ha de producirse?, es decir, qué proporciones de bienes públicos y/o privados; ¿cómo han de producirse?, es decir, lo relacionado con la combinación de factores; ¿para quién ha de producirse?, es decir, si para los contribuyentes, y entre estos, cuáles son los grupos más beneficiados y perjudicados; finalmente, ¿cómo se toman estas decisiones?, es decir, estudiar los procesos políticos independientes y la forma en que en estos se toman de manera colectiva o no las decisiones públicas. De acuerdo con lo anterior, es posible determinar los casos en los que el Estado es más eficiente que el mercado, o viceversa, tanto en la asignación de los recursos, como en la producción de bienes y servicios ya sean públicos o corrientes (Stiglitz y Rosengard, 2015).

Actualmente, los debates sobre los fallos del mercado están más vigentes que nunca; la reciente crisis ha generado controversias, por ejemplo, entre quienes defienden que el 
Editorial

sector privado es más eficiente en la producción de vacunas para enfrentar la COVID-19 y aquellos que defienden que las vacunas deberían ser consideradas un bien público, el cual pueda ser producido y suministrado por el Estado de manera más eficiente por medio de los servicios públicos de sanidad, dada la ineficiencia del mercado de suministrar vacunas a dos años de iniciada la pandemia. Uno de los objetivos de la presente edición y de la Revista Finanzas y Política Económica es precisamente contribuir en la realización de este debate.

\section{REFERENCIAS}

1. Cameron, R., y Neal, L. (2014). Historia económica mundial desde el paleolítico hasta el presente (4. ${ }^{a}$ ed.). Madrid: Alianza Editorial.

2. Feliu, G., y Sudrià, C. (2013). Introducción a la historia económica mundial (2. ${ }^{\mathrm{a}}$ ed.). Valencia: Universitad de Valencia. http://recursostic.educacion.es/secundaria/edad/4esohistoria/quincena1/ imagenes1/quincena1_texto.pdf

3. Keynes, J. M. (1934). The General Theory of Employment, Interest, and Money (1. ${ }^{\mathrm{a}}$ ed.). Cambridge: Palgrave Macmillan. https://doi.org/https://link.springer.com/book/10.1007\% 2F978-3-319-70344-2

4. Smith, A. (1776). An Inquiry Into the Nature and Causes of the Wealth of Nations (1. ${ }^{\mathrm{a}}$ ed.). Londres: University Of Chicago Press.

5. Stiglitz, J. E., y Rosengard, J. K. (2015). La economía del sector público (4. ${ }^{\mathrm{a}}$ ed.). Barcelona: Antoni Bosch. 